\section{Embryo Rescue of Cold-hardy Table Grapes}

\author{
Laise S. Moreira and Matthew D. Clark \\ Department of Horticultural Science, University of Minnesota-Twin Cities, \\ St. Paul, MN 55108
}

Additional index words. embryo rescue, cold-hardy grapes, table grapes

\begin{abstract}
Seedlessness is one of the most desirable traits for table and raisin grapes. Stenospermocarpic cultivars are desirable because they have large berries with superior quality. Embryo rescue techniques have been widely used to get progeny seedling populations from crosses using seedless mother plants. Selection of the female parent, sampling time, and the growth medium are the most crucial to the success of this technique. This study investigated the effect of best sampling time and media composition on embryo rescue efficiency in a cold-hardy hybrid grape breeding program. We sampled ovules 5 to 9 weeks after flowering, and we tested four media compositions. The greatest percentages of embryo germination and normal seedlings were obtained when ovules were harvest at 8 weeks after flowering, indicating that it is suitable to harvest ovules at veraison, when the extraction of ovules is easier as a result of softer berry flesh. For the media composition experiment, all ovules were harvested at 8 weeks after flowering. Nitsch \& Nitsch culture medium had very low germination, and the resulting seedlings performed the lowest compared with the other treatments. Lloyd \& McCown Woody Plant Basal Medium (WPM) increased the number of embryos germinated significantly, and a number of normal seedlings and plantlets developed. Although there was no significant difference among the other three media containing WPM supplemented with different doses of plant regulators, the WPM Plus medium [with cytokinin (6-benzlaminopurine), indole-3-butyric acid, gibberellin, and casein hydrolysate] promoted the greatest percentage of established plants $(46.98 \%)$. Therefore, the 8-weeks-after-flowering harvest time and the WPM Plus medium were selected for use in the embryo rescue protocol at the University of Minnesota grape breeding program.
\end{abstract}

Many characteristics define successful table grape cultivars, but seedlessness has become a defining feature for consumers. In response to this demand, $77 \%$ of 27,582 ha planted in California with table grapes are seedless varieties (U.S. Department of Agriculture, 2020). Surprisingly, $37 \%$ of the varieties grown were developed in the past decade. In grapevine, seedless berries can result from parthenocarpic and stenospermocarpic mechanisms. Stenospermocarpy results from the regular fertilization of the embryo and endosperm, but no viable seed is produced as a result of embryo abortion during development (Stout, 1936). The resultant berry contains a "seed trace," or underdeveloped ovule of varying size, which may or may not have an endosperm and can vary in integument lignification depending on the genetic background of the mother plant, environment, vine age, and rootstock (Christensen et al., 1983).

Received for publication 16 Mar. 2021. Accepted for publication 15 June 2021.

Published online 4 August 2021.

We thank the expert vineyard team Jennifer Thull, John Thull, and Colin Zumwalde for their technical support in vine management. Beth Lenau taught us the embryo rescue technique.

M.D.C. is the corresponding author. E-mail: clark776@umn.edu.

This is an open access article distributed under the CC BY-NC-ND license (https://creativecommons. org/licenses/by-nc-nd/4.0/).
Stenospermocarpic grape varieties are preferable because they produce fruit with large berries and better fruit quality (Akkurt et al., 2019). Thus, many seedless cultivars that have been developed are derived from 'Sultanina' (also known as 'Thompson Seedless') because of the heritable stenospermocarpic trait.

Table grape breeding programs have carried out hybridizations to obtain seedless cultivars to respond to market demand. Grape breeders have crossed seedless pollen donors with seeded mother plants for decades to get a proportion of seedless offspring each generation to advance cultivar development (Gray et al., 1990; Li et al., 2020b). In some seeded $\times$ seedless crosses, less than $10 \%$ of the $\mathrm{F}_{1}$ progeny are seedless; however, using two seedless parents, this value can reach $82 \%$ to $100 \%$ (Bharathy et al., 2005; Emershad et al., 1989; Ji et al., 2013; Ramming, 1990; Tian and Wang, 2008; Zhu et al., 2020).

Bouquet and Danglot (1996) hypothesized that seedlessness results from the expression of three complementary recessive genes regulated by a dominant inhibitor gene, which they identified as the seedlessness (SDI) gene. These early findings led to the genetic mapping of the stenospermocarpic locus and subsequent use of genetic markers at the SDI locus to expedite the breeding process by selecting against seeded progeny during the greenhouse stage. However, the progress, especially in the upper Midwest of the United
States, has been slow and limited in success. Currently, very few commercial grape growers in the upper Midwest report producing any of the available cultivars. In addition to selecting for the seedless trait, a breeder in the upper Midwest also must consider local climate adaptations (i.e., cold hardiness, frost-free period), disease resistance, berry size, and flavor. The highly productive, amateur grape breeder Elmer Swenson from Wisconsin released only two seedless cultivars, 'Petite Jewel' and 'Somerset Seedless', despite spending decades using this seeded $\times$ seedless crossing scheme (Clark, 2019). These varieties have small berries, contain a noticeable seed trace, and are rated as only moderately cold hardy in U.S. Department of Agriculture (USDA) hardiness zone $4 \mathrm{a}$.

The consumer perception of the seed trace is not necessarily correlated to size, but rather to the hardness of the seedcoat (Striem et al., 1992). In California and now widespread in private industry, breeders continue to select for nonperceived seed trace (reduced size and seedcoat hardness), and use embryo rescue techniques. To advance table grape breeding further, Cain et al. (1983) first reported using embryo rescue to extract developing ovules (and embryos) and grow them into established, whole plants using sterile, aseptic culture and nutrient media. The embryo rescue technique refers to an in vitro procedure used to promote an immature embryo's development into a viable plant by nurturing the embryo artificially via a supplemented culture medium.

Seedless $\times$ seedless crosses result in a greater proportion of seedless offspring, allowing for more chances at identifying elite stenospermic selections. Most breeding programs have historically focused on Vitis vinifera because of fruit quality, small seed trace, and targeted growing regions in Mediterranean climates. Other public breeding programs, notably the University of Arkansas, Cornell University, and University of Guelph, use diverse genetic backgrounds, including $V$. labrusca, for expanding the aroma profiles and cold hardiness of the germplasm. However, many biological and nonbiological factors influence the successful development of cultured embryos, including the maturity stage of ovules (and embryo), maternal genotype, culture medium, and culture environment (Ramming, 1990).

A limitation of the embryo rescue technique is the amount of skilled labor required to prepare and maintain sterile conditions and produce media, and the time-intensive process of embryo excision. As a result, the University of Minnesota grape breeding program initiated experiments in 2017 to determine the best protocols for advancing the cold-hardy table grape cultivar development pipeline. The breeding program uses highly complex pedigrees with multiple Vitis species, including $V$. vinifera, $V$. riparia, $V$. labrusca, $V$. aestivalis, and $V$. rotundifolia. No cold-hardy grape breeding program (USDA hardiness zone 4) has reported using embryo rescue techniques to advance research in this area. 
Table 1. Description of crosses used for the two experiments, including sampling date as days after flowering and growing degree day (GDD, base $10{ }^{\circ} \mathrm{C}$ ).

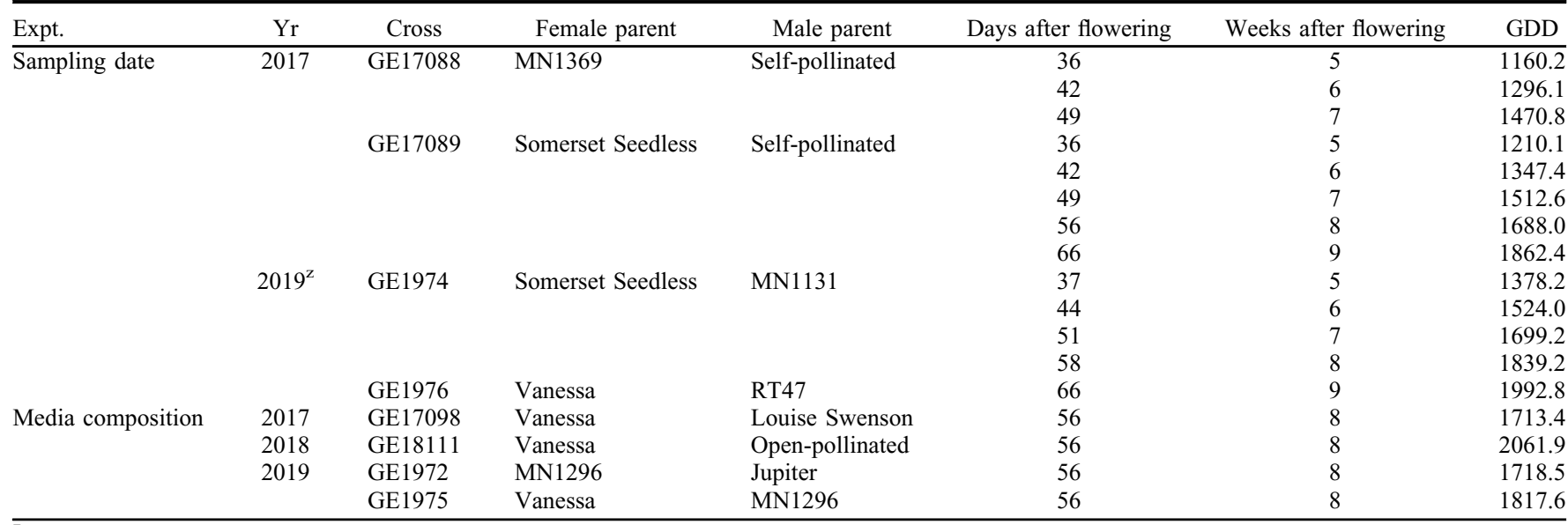

${ }^{\mathrm{z}}$ In 2019, each cross's sample times were the same, with one additional harvest at $66 \mathrm{~d}$ after flowering for GE1976.

The success rate for embryo rescue through ovule culture in grape is low, but it can vary from $1 \%$ to $89 \%$ (Bharathy et al., 2005; Emershad et al., 1989; Ji et al., 2013; Yang et al., 2007; Zhu et al., 2020). The developmental progression through in vitro culture of an ovule to a normal seedling is influenced by genotype, cultural conditions, and embryo development in the artificial environment (Li et al., 2015b). Various nutrient media have been tested in grapes (Gray et al., 1987), sampling time after flowering (Gray et al., 1990; Li et al., 2020b; Pommer et al., 1995), and length of ovule incubation as summarized by Li et al. (2015b). Selecting the germination media on which embryos are cultured can affect the development into normal plantlets or myriad aberrations (Ji et al., 2013). The outcome of embryo rescue culture relies primarily on the media composition used during two phases. The first phase (heterotrophic, in which the pre-embryo depends on the endosperm if present) consists of incubating the fertilized ovules on the media to aid embryo formation and avoid abortion. During the second phase (autotrophic, which usually begins in the late heart-shaped embryo stage), ovules are dissected to remove the embryo and are then placed onto a medium that supports embryo germination, which later leads to growth and development into normal plantlets (Ramming, 1990; Sharma et al., 1996).

The development of breeding families for cold-hardy, stenospermocarpic table grapes was pursued through several experiments starting in 2017 to determine the suitability of embryo rescue techniques to advance the breeding program. The unique genetic backgrounds and cold-climate growing conditions, including a short growing season in Minnesota, necessitated a comprehensive investigation into protocol development to apply the embryo rescue techniques efficiently-specifically, in ovulo embryo culture. The embryo rescue technique has allowed the production of interspecific and intergenic hybrids in the table grape breeding program. Protocols investigating the optimal sampling time for berry harvest and ovule extraction were tested over 2 years. The different compositions of nutrient media for germination were carried out over 3 years to identify effective standard operating procedures to obtain the greatest proportion of normal seedlings.

\section{Materials and Methods}

The parents and breeding selections for this experiment were grown at the University of Minnesota Horticultural Research Center, Excelsior, MN (lat. $44^{\circ} 52^{\prime} 08.1^{\prime \prime} \mathrm{N}$, long. $\left.93^{\circ} 38^{\prime} 17.3^{\prime \prime} \mathrm{W}\right)$. The parental cultivars and breeding selections included both cold-hardy and cold-sensitive plant materials (Tables 1 and 2). The cold-hardy cultivars (Louise Swenson, Somerset Seedless, and Vanessa) and breeding selections (MN1131, MN1296, MN1369, and RT47) were trained on a top wire, a high-cordon system, whereas the cold-sensitive varieties (Jupiter and Vanessa) were trained to the mini-J system for winter protection (Hoover and Hemstad, 1993).

Expt. 1: Determination of optimal sampling time. Optimal sampling timing for ovule extraction using a total of three seedless maternal genotypes and four populations was studied for 2 years. The maternal genotypes included MN1369, an advanced breeding selection, 'Somerset Seedless', a variety developed by Elmer Swenson, and 'Vanessa', a variety developed by the former Horticultural Research Institute of Ontario in Vineland, Ontario, Canada. In 2017, open- pollinated berries were collected at weekly intervals starting 5 weeks after flowering (WAF) for three time points for MN1369 (cross GE17088) and five time points for 'Somerset Seedless' (cross GE17089). In 2019, berries from 'Somerset Seedless' (cross GE1974) and 'Vanessa' (cross GE1976) were collected weekly at five time points starting $37 \mathrm{~d}$ after flowering or 5 WAF (Table 1). On average, 30 berries from each mother vine were harvested at 5 to $9 \mathrm{WAF}$. Variation in berry development is shown in Fig. 1 .

To provide additional context, the growing degree day (GDD) unit is reported for all sampling dates. GDD is a widely used method for predicting ripeness in grapevine by tracking heat accumulation units over a given period. The GDD data for the Horticultural Research Center were obtained from the Network for Environment and Weather application database (newa.cornell.edu; Carroll et al., 2011) using $10^{\circ} \mathrm{C}$ as a temperature base. For grapes in Minnesota, the period for tracking GDDs begins on $1 \mathrm{Apr}$. and goes through 31 Oct. (Haggerty, 2013).

In aseptic conditions under the laminar flow hood, berries were surface-sterilized using $70 \%$ ethanol for $2 \mathrm{~min}$, followed by rinsing two times with sterilized distilled water $\left(\mathrm{sdH}_{2} \mathrm{O}\right)$. Berries were then submerged in a solution of 3\% alkyldimethylbenzylammonium chloride (Pine-Sol Lemon Fresh; Clorox Company, Oakland, CA) for $2 \mathrm{~min}$

Table 2. Brief horticultural description of parents used in crosses.

\begin{tabular}{ll}
\hline Parent & \multicolumn{1}{c}{ Description } \\
Jupiter & $\begin{array}{c}\text { Black seedless table variety developed by the University of Arkansas; sweet, } \\
\text { not cold hardy } \\
\text { Seeded table and wine grape developed by Elmer Swenson; extremely hardy, } \\
\text { medium-size cluster, berries with aromatic flavor } \\
\text { Advanced seeded, black wine grape selection, cold hardy }\end{array}$ \\
MN1131 & $\begin{array}{l}\text { Advanced red grape selection, cold hardy, small seed trace } \\
\text { Labrusca-type aromatic white grape, firm texture, 20 }{ }^{\circ} \text { Brix at full ripeness, } \\
\text { medium-large seed trace }\end{array}$ \\
m1369 & $\begin{array}{c}\text { Seeded } V \text {. riparia-based rootstock selection, cold hardy } \\
\text { Red grape, firm texture, very sweet, achieving } 19-23^{\circ} \text { Brix at full ripeness, } \\
\text { Somerset Seedless } \\
\text { medium seed trace }\end{array}$ \\
Vanessa & $\begin{array}{c}\text { Red-skin variety, firm texture, medium-size cluster and berries, sweet flavor, } \\
\text { small seed trace }\end{array}$ \\
\hline
\end{tabular}




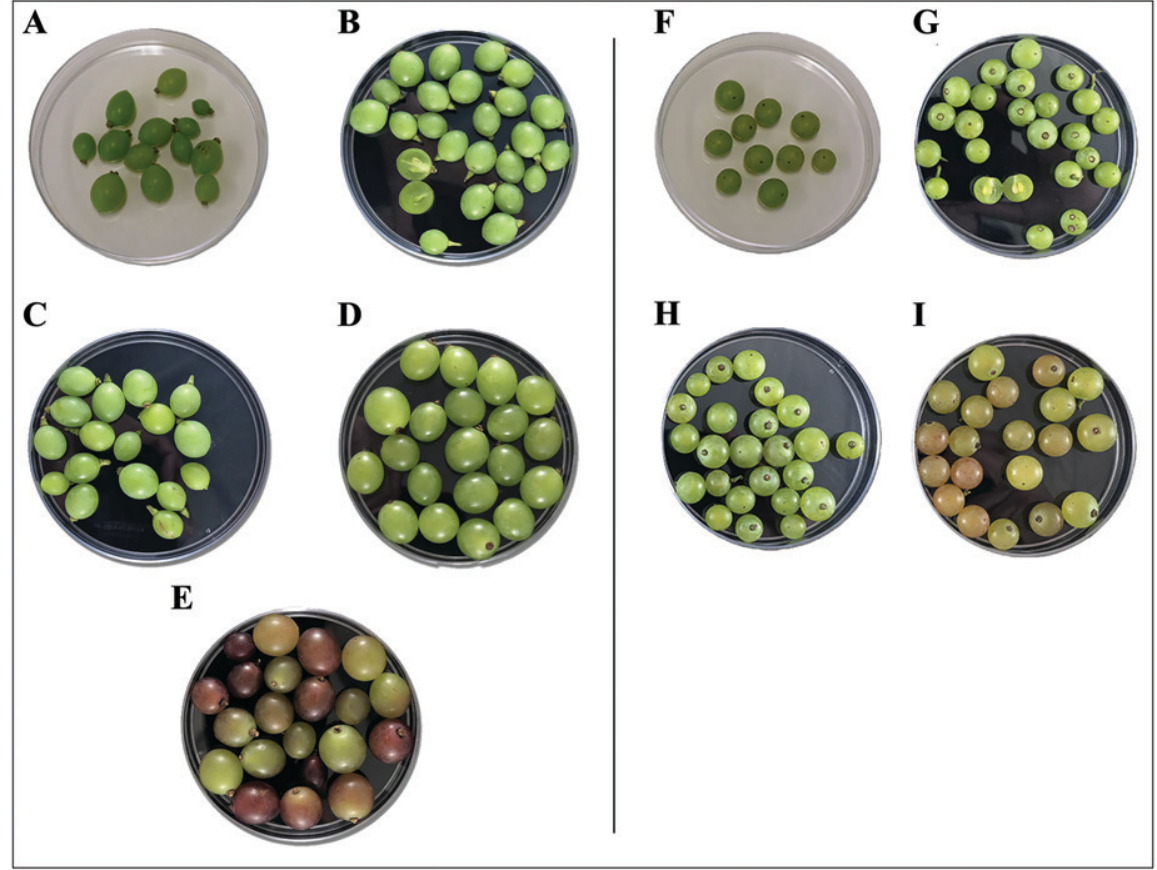

Fig. 1. Immature fruit harvested at different sampling times in weeks after flowering from population GE1974 at (A) 5 weeks, (B) 6 weeks, (C) 7 weeks, (D) 8 weeks, and (E) 9 weeks; and from population GE1976 at (F) 5 weeks, (G) 6 weeks, (H) 7 weeks, and (I) 8 weeks. and rinsed with $\mathrm{sdH}_{2} \mathrm{O}$ three times. Last, berries were submerged in $50 \%$ Clorox bleach, which contained $3.7 \%$ sodium hypochlorite (Clorox Company) with three drops of Tween 20, for $10 \mathrm{~min}$ and then rinsed three times with $\mathrm{sdH}_{2} \mathrm{O}$ (Emershad and Ramming, 1984). Sterilized berries were placed into sterile, $100 \times 15$ $\mathrm{mm}$ petri dishes. Berries were dissected using a flame-sterilized scalpel by cutting through the grape skin and pulp around the equator, and the ovules were dissected carefully from the pulp.

Ovules were cultured on a modified medium containing Lloyd \& McCown Woody Plant Basal Medium with Vitamins (WPM) (Lloyd and McCown, 1980) amended with $0.97 \mathrm{~g}$ 4-morpholineethanesulfonic acid monohydrate (Chemical Abstracts Services no. 145224-94-8), $60 \mathrm{~g}$ sucrose, 5.2 $\mathrm{g}$ agarose, and $3 \mathrm{~g}$ activated charcoal/1 L (Emershad and Ramming, 1994). The $\mathrm{pH}$ was adjusted to 5.7 with 1 M sodium hydroxide or $2 \mathrm{~m}$ hydrochloric acid before autoclaving. The media were autoclaved at $121^{\circ} \mathrm{C}$ for $30 \mathrm{~min}$. Petri plates with ovules were cultured incubation, the ovules were dissected under aseptic conditions using a stereo dissecting microscope with $25 \times$ magnification. A flame-sterilized scalpel was used to cut into the ovule, and the embryo was extracted from the endosperm and replated onto $15-\mathrm{mL}$ test tube slants with $10 \mathrm{~mL}$ WPM Plus medium (formula described in Table 3) for germination. Tubes were placed under T8 white fluorescent lights with $8 \mathrm{~h}$ of dark and $16 \mathrm{~h}$ of light at $21^{\circ} \mathrm{C}$. Activated charcoal was added to all media to reduce tissue browning, reduce contamination, and promote embryo development (Motoike et al., 2001). for 3 months in the dark at $\approx 20^{\circ} \mathrm{C}$. After
Expt. 2: Evaluating germination media composition. Four nutrient media-WPM with no plant growth regulator (PGR), WPM with 6-benzlaminopurine (BA), WPM Plus, and Nitsch \& Nitsch (Nitsch and Nitsch, 1969)—detailed in Table 3, were evaluated for germination metrics and the success of converting embryos into normal seedlings. For this experiment, ovules from four crosses were evaluated in 3 years: GE17098 ('Vanessa' $\times$ 'Louise Swenson'), GE18111 ('Vanessa' open-pollinated), GE 1972 (MN1296 × 'Jupiter'), and GE1975 ('Vanessa' $\times$ MN1296). Ovules were extracted at $8 \mathrm{WAF}$, and GDD values at harvest are shown in Table 1 .

The berries were surface-sterilized and dissected, and the ovules extracted and plated onto a media using the protocol stated for Expt. 1. After incubation in the dark for 3 months, the ovules were dissected, and the embryos were transferred to four different germination media.
Assessment and statistical analyses. For both experiments, data were collected on the number of ovules, the number of embryos, and quality metrics on the germinated embryos using three scales. All assessments were made by the same person to minimize subjectivity. The quality of embryo germination (QEG) was based on a 6-point categorical scale as follows: 0 , no cotyledon nor hypocotyl (absence of root and shoot); 1 , distorted cotyledons; 2 , hypocotyl formed with short root, but no cotyledon; 3 , hypocotyl formed with short root but cotyledon with little development (Fig. 2A); 4, normal seedlings (with root and shoot) (Fig. 2B); and 5, somatic embryogenesis. QEG was evaluated after 3 months of embryo incubation, and 1 day before plantlets were transferred to the greenhouse.

A 10-point categorical scale (A-J) was used to rate embryo development into normal seedlings and was modified from $\mathrm{Ji}$ et al. (2013) to include categories for dead embryos and somatic embryogenesis in vitro. Plantlet development was analyzed based on work by Raseira and Einhardt (2010), a 5-point scale with descriptors: 1, dead embryo; 2, white or green but without leaves; 3 , weak or dry tip; 4 , minimal growth; and 5, normal vigorous growth. The number of days to germination was assessed when a seedling's cotyledons or hypocotyl were visible. The percentage of embryo germination was calculated by dividing the average number of embryos germinated by the average number of embryos cultured. The percentage of normal seedlings was based on the average number of normal seedlings developed divided by the average number of embryos and ovules cultured. The normal seedlings were counted according to score A described by Ji et al. (2013).

The proportion of normal plantlets (excluding those that were dead or did not germinate) was compared among treatments using Pearson's $\chi^{2}$ test, binomial logistic regression in $\mathrm{R}$ package VCD (version 1.4-7) (Meyer et al., 2020), and Fisher's pairwise comparison tests with Bonferroni correction in R package fmsb (Nakazawa, 2019). Analysis of variance (ANOVA) was conducted using a linear model, in which cross and treatment effects were included in the model; however, only treatment effects are reported in most cases. ANOVA and mean comparisons (Duncan's test at the $5 \%$ level) were performed in $\mathrm{R}$ using
Table 3. Composition of different media treatments tested for embryo rescue: woody plant medium (WPM; Lloyd and McCown, 1980) with or without plant growth regulators (PGR), with vitamins, and Nitsch \& Nitsch (1969) medium. Doses were the final concentration in $1 \mathrm{~L}$ distilled water.

\begin{tabular}{|c|c|c|c|c|}
\hline Components & WPM no PGR & WPM with BA & WPM Plus & Nitsch \& Nitsch \\
\hline WPM (g) & 2.41 & 2.41 & 2.41 & - \\
\hline Nitsch \& Nitsch (g) & - & - & - & 5.32 \\
\hline Myo-inositol (g) & 0.10 & 0.10 & 0.10 & 0.10 \\
\hline Sucrose $(\mathrm{g})$ & 20.00 & 20.00 & 20.00 & 30.00 \\
\hline Activated charcoal $(\mathrm{g})$ & 3.00 & 3.00 & 3.00 & 2.00 \\
\hline Agarose $(\mathrm{g})$ & 7.00 & 7.00 & 7.00 & 4.00 \\
\hline $\mathrm{BA}(\mu \mathrm{M})$ & - & 4.4 & 4.4 & - \\
\hline Indole-3-butyric acid & - & - & $5.7 \mu \mathrm{M}$ & $0.0017 \mathrm{~g}$ \\
\hline Gibberellic acid & - & - & $1.4 \mu \mathrm{M}$ & $0.0005 \mathrm{~g}$ \\
\hline Casein hydrolysate $(\mathrm{g})$ & - & - & 0.50 & 0.40 \\
\hline Preservative mixture $(\mathrm{mL})$ & 2.00 & 2.00 & 2.00 & 2.00 \\
\hline
\end{tabular}


$\mathbf{A}$

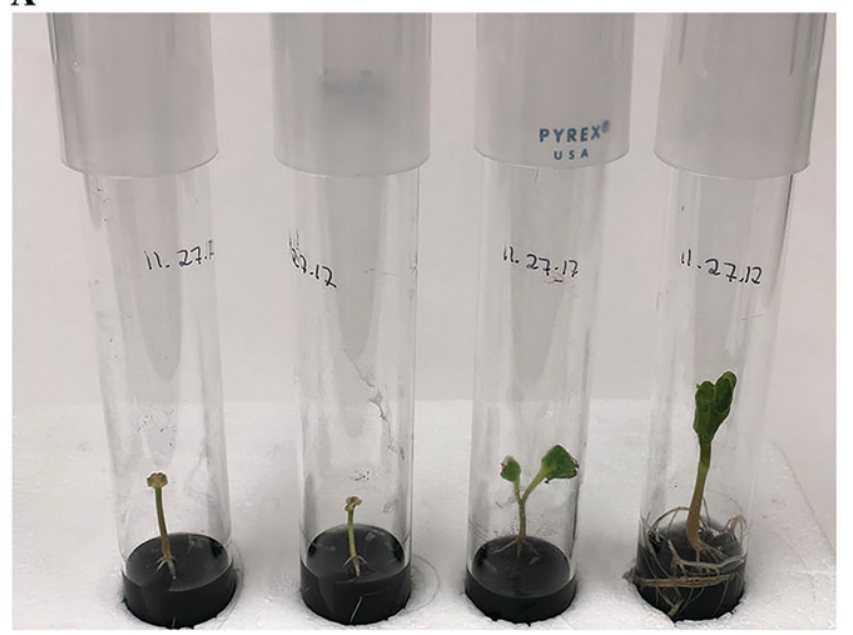

B

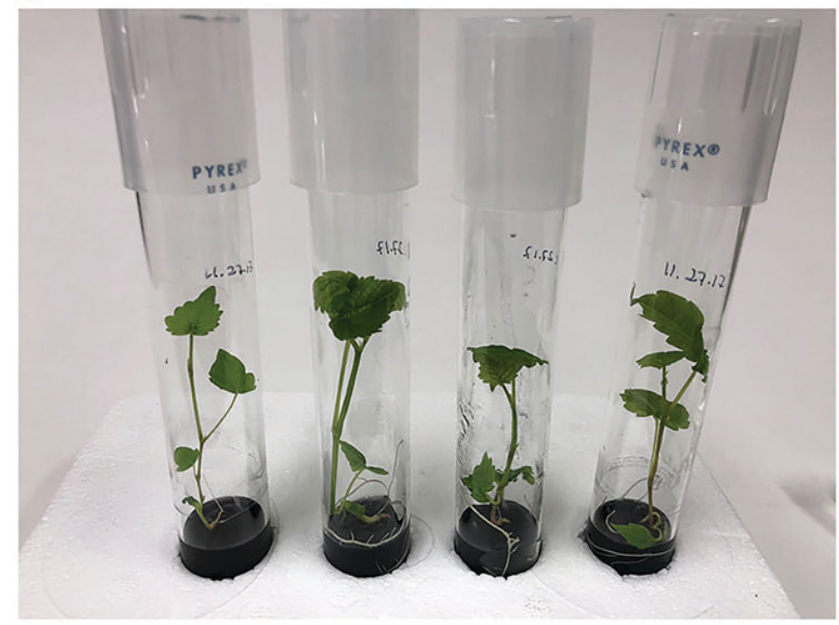

Fig. 2. Appearance of (A) example abnormal plantlets and (B) normal plantlets.

the 'agricolae' package (version 1.3-1) (de Mendiburu, 2019).

\section{Results}

A summary of descriptive statistics for all crosses and experiments for embryo recovery, germination, and development into normal seedlings is shown in Table 4, but it does not consider any experimental treatment effects. A total of 2119 ovules were cultured across both experiments, of which 845 ovules were converted into embryos, which corresponds
Expt. 1: Optimal sampling time. The effect of berry sampling time on embryo formation, germination, and plant development was tested using directed cross-pollinations and self-pollinations of seedless cultivars and advanced selections. Sampling time did not influence the mean number of embryos germinated and the mean normal seedling number across all weeks tested $(P>0.05$, Table $5)$. However, the days to germination was affected significantly when ovules were harvested at different weeks. Although embryos harvested at 6 weeks gave the numerically shortest days to germination $(9.39 \mathrm{~d}$ to germination), it was not significantly different from 8 weeks ( $9.76 \mathrm{~d}$ to germination) or 7 weeks (10.11 d to germination). Embryos had a greater percentage germination when harvested at weeks 5 and $8 \quad(78.02 \%$ and $91.30 \%$, respectively). Embryos extracted from ovules harvested at 9 WAF germinated poorly $(67.30 \%)$ and developed the lowest number of normal plantlets $(9.61 \%)$, indicating that embryos may have aborted before incubation. The greatest percentage of normal plants $(37.65 \%)$ was obtained when ovules were harvested at $8 \mathrm{WAF}$. The accumulated GDDs accounted for ovules harvested at 8 WAF were 1688 (in 2017) and 1839.2 (in 2019). Overall, 8 WAF coincided with veraison and was highly efficient for ovule extraction (Table 5).

The $\chi^{2}$ tests for independence were significant $(P<0.01)$ for seedling development, QEG, and plantlet development, indicating the trait and sampling week were not independent. Contingency tables were constructed for investigating additional trends and observations for sampling time averaged across all crosses. Cross GE17088 was only evaluated for weeks 5 to 7 after flowering, and GE1974 for weeks 5 to 8 after flowering. Overall, embryo death was less at 8 WAF than any other treatment. According to the QEG scale, 8 and 9 WAF had the lowest number of embryos with category 0 (alive but no cotyledon, hypocotyl, or root) than the first 3 sampling weeks.

Expt. 2: Media composition. Media composition influenced significantly the percentage embryo germination, the days to germination, and the percentage of normal plantlets developed (Table 6). Nitsch \& Nitsch medium showed the lowest performance for all traits analyzed. However, the three WPM-based

Table 4. Descriptive summary statistics of ovules cultured, and embryos recovered in eight table grape crosses at the University of Minnesota. Normal seedling development described as category "A" from Ji et al. (2013).

\begin{tabular}{|c|c|c|c|c|c|c|c|}
\hline \multirow[b]{2}{*}{ Cross } & \multirow{2}{*}{$\begin{array}{c}\text { Ovules } \\
\text { cultured (n) }\end{array}$} & \multirow{2}{*}{$\begin{array}{l}\text { Embryos } \\
\text { cultured (n) }\end{array}$} & \multirow{2}{*}{$\begin{array}{c}\text { Embryos } \\
\text { germinated (n) }\end{array}$} & \multirow{2}{*}{$\begin{array}{c}\text { Normal } \\
\text { seedlings (n) }\end{array}$} & \multirow{2}{*}{$\begin{array}{l}\text { Germinated } \\
\text { embryos }(\%)^{z}\end{array}$} & \multicolumn{2}{|c|}{ Basis of \% normal seedlings } \\
\hline & & & & & & No. of germinated embryos & No. of ovules cultured \\
\hline$\overline{\mathrm{GE} 17088}$ & 109 & 57 & 29 & 17 & 50.87 & 58.62 & 29.82 \\
\hline GE17089 & 246 & 104 & 68 & 13 & 65.38 & 19.11 & 12.50 \\
\hline GE1976 & 296 & 104 & 79 & 20 & 75.96 & 25.31 & 19.23 \\
\hline GE17098 & 204 & 115 & 90 & 30 & 78.26 & 33.33 & 26.09 \\
\hline GE18111 & 520 & 112 & 88 & 24 & 78.57 & 27.27 & 21.43 \\
\hline Total & 2119 & 845 & 611 & 223 & 72.31 & 36.50 & 26.39 \\
\hline
\end{tabular}

${ }^{\mathrm{z}}$ The number of embryos germinated/number of embryos cultured. 
Table 5. Effect of sampling date (week after flowering) on the development of normal plantlets for all crosses.

\begin{tabular}{|c|c|c|c|c|c|c|c|c|c|}
\hline \multirow[b]{2}{*}{$\begin{array}{l}\text { Week after } \\
\text { Flowering }\end{array}$} & \multirow{2}{*}{$\begin{array}{c}\text { Mean } \\
\text { embryos } \\
\text { culture (n) }\end{array}$} & \multirow{2}{*}{$\begin{array}{c}\text { Mean } \\
\text { embryos } \\
\text { germinated (n) }\end{array}$} & \multirow{2}{*}{$\begin{array}{c}\text { Embryos } \\
\text { germinated } \\
(\%)\end{array}$} & \multirow[b]{2}{*}{$\begin{array}{l}\text { Days to } \\
\text { germination }\end{array}$} & \multirow[b]{2}{*}{$\begin{array}{l}\text { Mean normal } \\
\text { seedling }\end{array}$} & \multicolumn{4}{|c|}{ Normal plantlets of total embryos cultured by treatment (\%) } \\
\hline & & & & & & $\begin{array}{l}\text { Germinated } \\
\text { embryos }^{\mathrm{z}}\end{array}$ & $\begin{array}{l}\text { Embryos } \\
\text { cultured }^{z}\end{array}$ & $\mathrm{QEG}^{\mathrm{y}}$ & $\begin{array}{c}\text { Plantlet } \\
\text { development }^{\mathrm{x}}\end{array}$ \\
\hline 5 & 22.75 & 17.75 & 78.02 & $11.90 \mathrm{a}^{\mathrm{w}}$ & 5.75 & 32.39 & 25.27 & 24.18 & 21.98 \\
\hline 7 & 20.25 & 11.75 & 58.02 & $10.11 \mathrm{~b}$ & 4.50 & 38.29 & 22.22 & 22.22 & 9.88 \\
\hline 8 & 23.00 & 21.00 & 91.30 & $9.76 \mathrm{~b}$ & 8.66 & 41.23 & 37.65 & 34.78 & 7.25 \\
\hline 9 & 26.00 & 17.50 & 67.30 & $12.73 \mathrm{a}$ & 2.50 & 14.28 & $9.61^{\mathrm{v}}$ & $9.62^{\mathrm{v}}$ & $1.92^{\mathrm{v}}$ \\
\hline
\end{tabular}

${ }^{\mathrm{z}}$ Normal plantlet described as category A from Ji et al. (2013).

${ }^{\mathrm{y}}$ Quality of embryo germination (QEG) category 4.

${ }^{\mathrm{x}}$ Normal plantlet described as category 5 from Raseira and Einhardt (2010).

${ }^{\text {w}}$ Values are presented as means. Based on Duncan's test, the column values followed by the same letter or without any letters are not significantly different from each other at $P \leq 0.05$.

vSignificantly lower treatment value compared with others using Fisher's multiple comparison test.

media (WPM no PGR, WPM Plus, and WPM with BA) tested did not differ significantly. The WPM Plus medium accelerated germination of embryos (12.70 d) and promoted the greatest percentage of normal seedlings $(46.98 \%, P>0.05)$ (Table 6). In terms of plant normality, the Nitsch \& Nitsch medium had the lowest results for QEG (8.41), seedling development (9.35), and plantlet development (3.73). WPM Plus showed the highest results for QEG (34.23) and seedling development (35.14), which led to an increase in embryo rescue efficiency by the successful number of normal plants formed.

The $\chi^{2}$ tests for independence were significant $(P<0.01)$ for QEG; normal plantlet development indicating the trait and media composition were not independent. Contingency tables were constructed for investigating media composition for each cross and then averaged across all crosses to identify additional trends. The Nitsch \& Nitsch media had the greatest number of dead embryos and the greatest number of embryos with distorted fold-like cotyledons or no root formation $(\mathrm{QEG}=0)$. As seen in Table 4, GE1975 had the greatest number of dead embryos (69\%). For seedling development, the Nitsch $\&$ Nitsch media has the greatest number of undeveloped embryos (category 0) and the lowest value for category 4 (normal seedlings, with root and shoot). For plantlet development ratings, WPM Plus was lower for category 2 (white or green seedling without leaves) compared with all other treatments.

\section{Discussion}

Embryo rescue techniques have been studied primarily using $V$. vinifera cultivars and were developed to aid seedless table grape breeding under Mediterranean climate conditions with different phenological and developmental benchmarks than those in cold-hardy hybrid grape production and breeding programs like that of Minnesota. More recent reports using cold-hardy varieties (mostly from the University of Arkansas: 'Venus', 'Neptune', and 'Jupiter') have emerged from China (Guo et al., 2015; Liu et al., 2016; Zhu et al., 2020). Developing breeding program-specific embryo rescue techniques for extreme cold-hardy germplasm (USDA zone 4) in Minnesota was imperative to achieve the greatest number of surviving plants in a generally inefficient and laborious process. Genotype, sampling time, and media composition were confirmed to play essential roles in embryo rescue efficiency. In our study, germination ranged from $31.00 \%$ to $89.74 \%$ (Table 4 ). These results are comparable or superior to other values reported in the literature ( $\mathrm{Li}$ et al., 2014, 2020b; Liu et al., 2008; Zhu et al., 2020). Among the eight crosses tested, GE1972 and GE1974 had the greatest percentage of normal plantlets $(40.44 \%$ and $43.59 \%$, respectively). GE1975 had 31\% germination, which was greater than $16.2 \%$ germination rate reported by $\mathrm{Li}$ et al. (2014), who studied ovules from 'Crimson Seedless' $\times$ 'Flame Seedless' harvested at $60 \mathrm{~d}$ after flowering and cultured using the WPM Plus medium. Our result is promising, considering that GE1975 is a cross between two seedless parents. Despite the high percentage of embryo germination, the conversion rate to normal plantlets (13\%) was comparable to that of Li et al. (2014), who reported $12.5 \%$.

Sampling time is a critical factor in embryo development and, consequently, embryo rescue efficiency. Our study did not investigate embryo development specifically to reduce the handling of extracted embryos from the ovules. Based on the literature, many dates are proposed as optimal sampling times, varying from 39 to $70 \mathrm{~d}$ after flowering (Bharathy et al., 2003; Gray et al., 1990; Li et al., 2014, 2015a, 2020b; Liu et al., 2008; Zhu et al., 2020). GDD can be a viable predictor for sampling time. Days after flowering or WAF are locally dependent, which means that plants in Minnesota under certain WAF will be at different phenological stages from plants under the same WAF in California. In this scenario, GDD can be more suitable than harvest day or week after flowering because it offers a better prediction of plant phenological progression by accounting for climate variations that can occur from year to year (Haggerty, 2013). For this study, we did not test different GDD sampling dates, but report the GDD associated with each week of sampling to provide a baseline for future investigation.

Stout (1936) proposed that seed abortion occurs soon after fertilization at the early phenological stage of berry development. In

Table 6. Effect of media selection (including woody plant medium on the development of normal plantlets for all crosses.

\begin{tabular}{|c|c|c|c|c|c|c|c|c|c|}
\hline \multirow[b]{2}{*}{ Medium } & \multirow{2}{*}{$\begin{array}{c}\text { Mean } \\
\text { embryos } \\
\text { culture (n) }\end{array}$} & \multirow[b]{2}{*}{$\begin{array}{l}\text { Mean embryos } \\
\text { germinated (n) }\end{array}$} & \multirow{2}{*}{$\begin{array}{c}\text { Embryos } \\
\text { germinated } \\
(\%)\end{array}$} & \multirow[b]{2}{*}{$\begin{array}{c}\text { Days to } \\
\text { germination }\end{array}$} & \multirow[b]{2}{*}{$\begin{array}{l}\text { Mean normal } \\
\text { seedling }\end{array}$} & \multicolumn{4}{|c|}{ Normal plantlets of total embryos cultured by treatment $(\%)$} \\
\hline & & & & & & $\begin{array}{l}\text { Germinated } \\
\text { embryo }(\%)^{\mathrm{z}}\end{array}$ & $\begin{array}{c}\text { Embryos } \\
\text { cultured }(\%)^{\mathrm{z}}\end{array}$ & QEG $(\%)^{\mathrm{y}}$ & $\begin{array}{c}\text { Plantlet } \\
\text { development }(\%)^{\mathrm{x}}\end{array}$ \\
\hline Nitsch \& Nitsch & 26.75 & $15.25 \mathrm{~b}^{\mathrm{w}}$ & 57.00 & $16.58 \mathrm{~b}$ & $2.5 \mathrm{~b}$ & 16.39 & $9.35^{\mathrm{v}}$ & $8.41^{\mathrm{v}}$ & $3.73^{\mathrm{v}}$ \\
\hline WPM no PGR & 28.25 & $21.75 \mathrm{a}$ & 76.99 & $13.39 \mathrm{a}$ & $8.75 \mathrm{a}$ & 40.22 & 30.97 & 30.01 & 24.78 \\
\hline WPM Plus & 27.75 & $20.75 \mathrm{a}$ & 74.77 & $12.70 \mathrm{a}$ & $9.75 \mathrm{a}$ & 46.98 & 35.14 & 34.23 & 21.62 \\
\hline WPM with BA & 28.25 & $20.75 \mathrm{a}$ & 73.45 & $14.61 \mathrm{ab}$ & $8.50 \mathrm{a}$ & 40.96 & 30.01 & 30.01 & 24.78 \\
\hline
\end{tabular}

${ }^{\mathrm{z}}$ Normal plantlet described as category A from Ji et al. (2013).

${ }^{\mathrm{y}}$ Quality of embryo germination (QEG) category 4.

${ }^{\mathrm{x}}$ Normal plantlet described as category 5 from Raseira and Einhardt (2010).

${ }^{\text {w}}$ Values are presented as means. Based on Duncan's test, the column values followed by the same letter or without any letters are not significantly different from each other at $P \leq 0.05$.

${ }^{v}$ Significantly lower treatment value compared with others using Fisher's multiple comparison test.

$\mathrm{WPM}=$ woody plant medium; $\mathrm{PGR}=$ plant growth regulator; $\mathrm{BA}=6$-benzlaminopurine . 
our study, ovules harvested from 5 to 8 WAF had viable embryos, and embryo germination and plant recovery rates increased numerically when embryos were harvested at $8 \mathrm{WAF}$. These findings agree with those of Emershad et al. (1989) and Gray et al. (1990), who noted that embryo abortion occurs much later, even after veraison. Although 7 WAF showed the lowest germination rate $(58.02 \%)$, it had a greater number of normal plantlets than at $9 \mathrm{WAF}$. The low success rate at $7 \mathrm{WAF}$ requires additional investigation. In Minnesota, this is the week leading up to veraison. This sampling time point may coincide with embryo development that is unsuitable for ovule culture or possible hormonal regulation or signaling associated with berry softening and ripening at the end of the lag phase (Keller, 2020; Li et al., 2020b).

The embryo germination period can be longer depending on how well the embryo develops, often characterized by shape, the hybrid combination, and the ovule excision time (Amaral et al., 2001; Li et al., 2015a). Our data did not show any consistent trend for days to germination. Bharathy et al. (2003) studied different cross combinations between 'Thompson Seedless' and eight seeded varieties, and reported that embryos from 'Thompson Seedless' $\times V$. tilifolia germinated within $5 \mathrm{~d}$, but embryo shape (i.e., development) influenced when the embryo germinated. Based on their findings, embryos with globular shapes took longer to germinate or did not germinate at all.

Our study demonstrates that $8 \mathrm{WAF}$ GDD accumulation around 1688.0 units (in 2017) and 1839.2 units (in 2019) - is the optimal time to harvest ovules in Minnesota at the transition to veraison for the varieties and breeding selections studied. Unlike other traditional grape-growing regions, Minnesota has a short season (Supplemental Table 1) and, consequently, a short flowering window, partly because of the genetic background based in $V$. riparia. Therefore, cultivars grown in Minnesota have phenology different from $V$. vinifera as a result of genetic and environmental factors (personal observation). Ovule extraction at veraison was easier in this project because of the softer berry flesh and increased ovule size. We believe that future studies considering a wider range of GDD could be done to improve embryo rescue efficiency by determining the best optimal time to harvest ovules. Additional consideration could be made for GDD at bloom, and accumulation of GDD between bloom and the embryo rescue procedures.

During the past decade, WPM has been one of the most reported media for embryo rescue studies, mainly with testing on different levels of BA or indole-3-acetic acid to increase the rate of plant development (Guo et al., 2015; Li et al., 2014; Liu et al., 2016; Nookaraju et al., 2007). Unlike many studies that have focused on trying specific plant growth regulator concentrations, our primary goal was to determine which media composition was more suitable for embryo rescue technique to develop seedless table grapes in Minnesota.

The WPM Plus medium was proposed by Li et al. (2014), and they reported embryo germination of $15.4 \%$ to $55.4 \%$ and normal plantlet development of $11.15 \%$ to $44.6 \%$. In our study, the percentage of normal plantlets varied from $16.39 \%$ to $46.98 \%$ using four medium treatments (Table 6). Independent of plant material, the WPM Plus medium supplemented with PGR [cytokinin (BA), indole-3-butyric acid, gibberellic acid, and casein hydrolysate $(\mathrm{CH})]$ in the culture medium showed the greatest number of normal plantlets $(46.98 \% ; P>0.05)$. In agreement with $\mathrm{Li}$ et al. (2020b), these results demonstrated that the WPM medium with BA helped embryos germinate into normal plantlets $(\approx 35 \%$ to $68.9 \%)$ and reduced the abnormal plantlet development percentage (from $\approx 55 \%$ to $18.9 \%$ ). Zhu et al. (2020) studied different media compositions and found that the best embryo germination and plantlet formation medium was WPM with $0.2 \mathrm{mg} \cdot \mathrm{L}^{-1} \mathrm{BA}$ and $0.1 \mathrm{mg} \cdot \mathrm{L}^{-1}$ indole- 3 -acetic acid. Jiao et al. (2018) also reported that WPM medium supplemented with 0.2 $\mathrm{mg} \cdot \mathrm{L}^{-1} \mathrm{BA}$ promoted an embryo germination rate of $43 \%$ and $40 \%$ in ovules of 'Ruby Seedless' $x$ 'Zixiang Seedless'. In our study, WPM containing PGRs did not differ statistically between the two media containing WPM, suggesting that PGR modifications to culture media were not strictly necessary in the germplasm studied.

Emershad et al. (1989), Gray et al. (1990), and $\mathrm{Li}$ et al. (2020b) reported that media supplemented with different PGRs, independently or in combination, affected embryo recovery in cultured ovules. $\mathrm{CH}$ is another important component of the WPM Plus medium, providing an additional amino acid source. The Australian Grape Breeding program (Commonwealth Scientific and Industrial Research Organisation) used a basal medium reported by Bouquet and Davis (1989) supplemented with $\mathrm{CH}$ to ensure a high number of embryo recoveries, which resulted in about $\approx 10 \%$ and $8 \%$ for embryo recovery and emergence, respectively (Liu et al., 2008). Again, our results show that the addition of $\mathrm{CH}$ was not strictly necessary in the germplasm studied.

In our study, the Nitsch \& Nitsch culture medium had the lowest percentage of germination and normal plantlets. These results are contrary to those of Ebadi et al. (2016), who reported a greater percentage of embryo germination and plant development when ovules were cultured on Nitsch \& Nitsch medium. WPM medium promoted significantly faster germination than the Nitsch \& Nitsch treatment (Table 6).

\section{Conclusion}

Embryo rescue techniques have affected table grape breeding significantly, contributing to seedless cultivar development with the complete sensory perception of seedlessness or small seed trace acceptable to consumers.
The embryo rescue technique used to test sampling time and media selection in our experiment effectively produced normal plantlets. For cold-climate grapes, harvesting ovules at 8 weeks (56-58 d) after flowering numerically promoted early germination $(9.76 \mathrm{~d})$ and resulted in the greatest number of normal seedlings developed (37.65). The WPM Plus medium increased the number of normal seedlings. Our study shows that WPM Plus is the most suitable medium for embryo rescue techniques. For this reason, it was adopted by the University of Minnesota breeding program to develop cold-hardy seedless table grapes in Minnesota.

\section{Literature Cited}

Akkurt, M., H. Tahmaz, and S. Veziroğlu. 2019. Recent developments in seedless grapevine breeding. S. Afr. J. Enol. Viticult. 40(2):1-1, doi: $10.21548 / 40-2-3342$.

Amaral, A.L., P.R.D.D. Oliveira, A.B.C. Czermainski, and U.A. Camargo. 2001. Estádios de desenvolvimento de embriões na obtenção de plantas em cruzamentos entre genitores apirenos de videira. Rev. Bras. Frutic. 23(3):647-651. 10.1590/S0100-29452001000300041.

Bharathy, P.V., G.S. Karibasappa, A.B. Biradar, D.D. Kulkarni, A.U. Solanke, S.G. Patil, and D.C. Agrawal. 2003. Influence of pre-bloom sprays of benzyladenine on in vitro recovery of hybrid embryos from crosses of Thompson Seedless and 8 seeded varieties of grape (Vitis spp.). Vitis 42(4):199-202.

Bharathy, P.V., G.S. Karibasappa, S.G. Patil, and D.C. Agrawal. 2005. In ovulo rescue of hybrid embryos in Flame Seedless grapes: Influence of pre-bloom sprays of benzyladenine. Scientia Hort. 106:353-359, doi: 10.1016/j.scienta.2005. 04.002 .

Bouquet, A. and Y. Danglot. 1996. Inheritance of seedlessness in grapevine (Vitis vinifera L.). Vitis $35: 35-42$.

Bouquet, A. and H.P. Davis. 1989. In vitro ovule and embryo culture for breeding seedless table grapes (Vitis vinifera L.). Agronomie 9:565-574.

Cain, D.W., R.L. Emershad, and R.E. Tarailo. 1983. In-ovulo embryo culture and seedling development of seeded and seedless grapes (Vitis vinifera $\mathrm{L}$.). Vitis 22:9-14.

Carroll, J., T. Weigle, and C. Petzoldt. 2011. The Network for Environment \& Weather Applications (NEWA). N. Y. Fruit Qrtly. 19:5-9, $<$ newa.cornell.edu $>$.

Christensen, P., D. Ramming, and H. Andris. 1983. Seed trace content of Fiesta grapes. Amer. J. Enol. Viticult. 34:257-259.

Clark, M.D. 2019. Development of cold climate grapes in the upper midwestern US: The pioneering work of Elmer Swenson. Plant Breed. Rev. 43:31-60, doi: 10.1002/9781119616801.ch2.

de Mendiburu, F. 2019. Agricolae: Statistical procedures for agricultural research. $\mathrm{R}$ package version 1:3-3. 15 Oct. 2020. <https://CRAN. R-project.org/package $=$ agricolae $>$.

Ebadi, A., M. Aalifar, M. Farajpour, and M.R. Fatahi Moghaddam. 2016. Investigating the most effective factors in the embryo rescue technique for use with 'Flame Seedless' grapevine (Vitis vinifera). J. Hort. Sci. Biotechnol. 91(5):441-447, doi: $10.1080 / 14620316.2016 .1162026$.

Emershad, R.L. and D.W. Ramming. 1984. In-ovulo embryo culture of Vitis vinifera L. cv. 'Thompson seedless'. Amer. J. Bot. 71(6):873-877.

Emershad, R.L. and D.W. Ramming. 1994. Somatic embryogenesis and plant development from 
immature zygotic embryos of seedless grapes (Vitis vinifera L.). Plant Cell Rep. 14(1):6-12.

Emershad, R.L., D.W. Ramming, and M.D. Serpe. 1989. In ovulo embryo development and plant formation from stenospermic genotypes of Vitis vinifera. Amer. J. Bot. 76(3):397-402.

Gray, D.J., J.A. Mortensen, C.M. Benton, R.E. Durham, and G.A. Moore. 1990. Ovule culture to obtain progeny from hybrid seedless bunch grapes. J. Amer. Soc. Hort. Sci. 115:1019-1024, doi: 10.21273/JASHS.115.6.1019.

Gray, D.J., L.C. Fischer, and J.A. Mortensen. 1987. Comparison of methodologies for in ovule embryo rescue of seedless grapes. HortScience 22:1334-1335.

Guo, X., W. Chen, Y. Guo, Z. Liu, H. Lin, J. Tang, and Y. Zhao. 2015. Influencing factors of embryo rescue in seedless grape. Pak. J. Bot. 47(2):669-673.

Haggerty, L.L. 2013. Ripening profile of grape berry acids and sugars in University of Minnesota wine grape cultivars, select Vitis vinifera, and other hybrid cultivars. Minnesota University-Twin Cities, MS Diss.

Hoover, E. and P. Hemstad. 1993. Growing grapes for home use. University of Minnesota Extension Publication AG-FO-1103-8.

Ji, W., Z. Li, W. Yao, P. Gong, and Y. Wang. 2013. Abnormal seedlings emerged during embryo rescue and its remedy for seedless grape breeding. Kor. J. Hort. Sci. Technol. 31:483-489, doi: 10.7235/hort.2013.12158.

Jiao, Y., Z. Li, K. Xu, Y. Guo, C. Zhang, T. Li, Y. Jiang, G. Liu, and Y. Xu. 2018. Study on improving plantlet development and embryo germination rates in in vitro embryo rescue of seedless grapevine. N. Z. J. Crop Hort. Sci. 46(1):39-53, doi: 10.1080/01140671.2017.1338301.

Keller, M. 2020. The science of grapevines. 3rd ed. Academic Press, Cambridge, MA, doi: 10.1016/B978-0-12-816365-8.00002-6.

Li, G.R., W. Ji, G. Wang, J.X. Zhang, and Y.J. Wang. 2014. An improved embryo-rescue protocol for hybrid progeny from seedless Vitis vinifera grapes $\times$ wild Chinese Vitis species. In Vitro Cell. Dev. Biol. Plant 50:110-120, doi: 10.1007/s11627-013-9543-7.
Li, J., X. Wang, X. Wang, and Y. Wang. 2015b. Embryo rescue technique and its applications for seedless breeding in grape. PCTOC 120(3): 861-880, doi: 10.1007/s11240-014-0656-4.

Li, S., K. Liu, S. Yu, S. Jia, S. Chen, Y. Fu, F. Sun, Q. Luo, and Y. Wang. 2020b. The process of embryo abortion of stenospermocarpic grape and it develops into plantlet in vitro using embryo rescue. PCTOC 143:389-409, doi: 10.1007/s11240-020-01926-y.

Li, S., Z. Li, Y. Zhao, J. Zhao, Q. Luo, and Y. Wang. 2020a. New disease-resistant, seedless grapes are developed using embryo rescue and molecular markers. Biotechnology 10(1):4, doi: 10.1007/s13205-019-1993-0.

Li, Z., T. Li, Y. Wang, and Y. Xu. 2015a. Breeding new seedless grapes using in ovule embryo rescue and marker-assisted selection. In Vitro Cell. Dev. Biol. 51:241-248, doi: 10.1007/ s11627-015-9677-X.

Liu, Q., J. Zhang, Y. Wang, D. Yu, and H. Xia. 2016. Breeding for cold-resistant, seedless grapes from Chinese wild Vitis amurensis using embryo rescue. N. Z. J. Crop Hort. Sci. 44(2):136-151, doi: 10.1080/01140671.2016.1153489.

Liu, S.M., S.R. Sykes, and P.R. Clingeleffer. 2008. Effect of culture medium, genotype, and year of cross on embryo development and recovery from in vitro cultured ovules in breeding stenospermocarpic seedless grape varieties. Aust. J. Agr. Res. 59:175-182, doi: 10.1071/AR07165.

Lloyd, G. and B. McCown. 1980. Commerciallyfeasible micropropagation of mountain laurel, Kalmia latifolia, by use of shoot-tip culture. Proc. Intl. Plant Propagators Soc. 30:421-427.

Meyer, D., A. Zeileis, and K. Hornik. 2020. vcd: Visualizing categorical data. R package version 1.4-7. 30 June 2021. <https://CRAN.R-project. org $/$ package $=$ vcd $>$.

Motoike, S.Y., R.M. Skirvin, M.A. Norton, and A.G. Otterbacher. 2001. Somatic embryogenesis and long-term maintenance of embryogenic lines from fox grapes. PCTOC 66:121-131, doi: 10.1023/A:1010604628865.

Nakazawa, M. 2019. fmsb: Functions for medical statistics book with some demographic data. R package version 0.7.0. <https://CRAN.R-project.org/ package $=\mathrm{fmsb}>$.
Nitsch, J.P. and C. Nitsch. 1969. Haploid plants from pollen grains. Science 163(3862):85-87.

Nookaraju, A., M.S. Barreto, G.S. Karibasappa, and D.C. Agrawal. 2007. Synergistic effect of CPPU and benzyladenine on embryo rescue in six stenospermocarpic cultivars of grapevine. Vitis 46(4):188-191, doi: 10.5073/vitis.2007. 46.188-191.

Pommer, C.V., D.W. Ramming, and R.L. Emershad. 1995. Influence of grape genotype, ripening season, seed trace size, and culture date on in ovule embryo development and plant formation. Bragantia 54:237-249, doi: 10.1590/S0006-8705 1995000200002 .

Ramming, D.W. 1990. The use of embryo culture in fruit breeding. HortScience 25:393-398.

Raseira, M.D.C.B. and P.M. Einhardt. 2010. Resgate de embriões em pessegueiro: Tempo de incubação. Sci. Agrar. 11(6):445-450, doi: 10.5380/rsa.v11i6.20390.

Sharma, D.R., R. Kaur, and K. Kumar. 1996. Embryo rescue in plants: A review. Euphytica 89(3):325-337.

Stout, A. 1936. Seedlessness in grapes. New York Agr. Expt. Sta. Tech. Bul. 238.

Striem, M.J., P. Spiegel-Roy, J. Baron, and R. Sahar. 1992. The degree of development of the seedcoat and the endosperm as separate sub-traits of stenospermocarpic seedlessness in grapes. Vitis 31:149-155, doi: 10.5073/vitis.1992.31.149-155.

Tian, L. and Y. Wang. 2008. Seedless grape breeding for disease resistance by using embryo rescue. Vitis 47(1):15, doi: 10.5073/vitis.2008.47.15-19.

U.S. Department of Agriculture. 2020. Grape acreage report 2019 crop. U.S. Department of Agriculture, Sacramento, CA. 1 Nov. 2020. < https://www. nass.usda.gov/Statistics_by_State/California/ index.php $>$.

Yang, D., W. Li, S. Li, X. Yang, J. Wu, and Z. Cao. 2007. In vitro embryo rescue culture of F1 progenies from crosses between diploid and tetraploid grape varieties. Plant Growth Regulat 51(1):63-71, doi: 10.1007/s10725-006-9148-9.

Zhu, P., B. Gu, P. Li, X. Shu, X. Zhang, and J. Zhang. 2020. New cold-resistant, seedless grapes developed using embryo rescue and markerassisted selection. PCTOC 140(3):551-562, doi: 10.1007/s11240-019-01751-y. 
Supplemental Table 1. Meteorological data of the study in 2017, 2018, and 2019 from the University of Minnesota Horticultural Research Center, Excelsior, MN.

\begin{tabular}{|c|c|c|c|c|c|c|c|c|c|c|c|c|c|c|c|c|c|c|}
\hline \multirow[b]{3}{*}{ Month } & \multirow{2}{*}{\multicolumn{3}{|c|}{ Growing degree days $\left({ }^{\circ} \mathrm{C}\right)$}} & \multicolumn{9}{|c|}{ Temperature $\left({ }^{\circ} \mathrm{C}\right)$} & & & & & & \\
\hline & & & & \multicolumn{3}{|c|}{ Avg. } & \multicolumn{3}{|c|}{ Maximum } & \multicolumn{3}{|c|}{ Minimum } & \multicolumn{3}{|c|}{ Rainfall (mm) } & \multicolumn{3}{|c|}{ Relative humidity, h $(90 \%)$} \\
\hline & 2017 & 2018 & 2019 & 2017 & 2018 & 2019 & 2017 & 2018 & 2019 & 2017 & 2018 & 2019 & 2017 & 2018 & 2019 & 2017 & 2018 & 2019 \\
\hline January & 0.0 & 0.0 & 0.0 & -6.77 & -8.9 & -10.8 & 4.9 & 7.0 & 7.5 & -24.3 & -26.5 & -33.9 & 10.1 & 3.5 & 0.5 & 229 & 114.0 & 4.0 \\
\hline February & 0.0 & 0.0 & 0.0 & -1.16 & -9.5 & -11.1 & 16.4 & 9.5 & 3.6 & -18.4 & -23.1 & -23.8 & 17.2 & 10.6 & 7.6 & 80.0 & 91.0 & 76.0 \\
\hline March & 0.0 & 0.0 & 0.0 & 0.38 & -0.5 & -2.5 & 19.0 & 9.0 & 16.4 & -15.6 & -13.0 & -27.7 & 19.0 & 18.7 & 53.5 & 90.0 & 104.0 & 33.0 \\
\hline April & 70.9 & 29.6 & 50.3 & 9.2 & 2.4 & 7.2 & 23.1 & 28. & 25.2 & -0.5 & -14.7 & -3.7 & 99.06 & 23.6 & 76.4 & 145 & 110.0 & 2.0 \\
\hline May & 256.3 & 519.7 & 182.0 & 14.22 & 18.8 & 12.6 & 28.94 & 37.3 & 30.4 & 1.6 & 6.0 & 1.4 & 130.3 & 95.2 & 161.2 & 124 & 34.0 & 4.0 \\
\hline June & 589.2 & 628.9 & 551.6 & 20.72 & 21.5 & 20.0 & 32.72 & 37.2 & 32.0 & 10.22 & 12.1 & 7.3 & 135.63 & 92.2 & 83.5 & 97 & 8.0 & 0.0 \\
\hline July & 746.2 & 731.9 & 740.1 & 22.8 & 22.6 & 22.7 & 34.22 & 34.5 & 33.6 & 14.2 & 13.0 & 13.6 & 98.29 & 90.4 & 145.7 & 100 & 7.0 & 96.0 \\
\hline August & 547.1 & 699.4 & 599.5 & 19.16 & 22.2 & 20.3 & 31.3 & 33.1 & 30.2 & 11.33 & 10.6 & 11.1 & 108.2 & 25.14 & 137.92 & 224 & 19.0 & 143.0 \\
\hline Total & 2209.7 & 2609.5 & 2213.5 & - & - & - & - & - & - & - & - & - & 614.78 & 359.34 & 666.32 & 1089 & 487 & 358 \\
\hline
\end{tabular}

